\title{
Differences in surface roughness of enamel after whey-extract application and CPP-ACP in post extracoronal-tooth bleaching
}

\author{
Afiatul Mukarromah*, Irfan Dwiandhono**, Dian Noviyanti Agus Imam** \\ *Dentistry, Universitas Jenderal Sudirman, Purwokerto, Central Java, Indonesia \\ **Department of Dental Conservation, Dentistry, Universitas Jenderal Sudirman, Purwokerto, Central Java, Indonesia \\ ***Department of Dental Materials, Dentistry, Universitas Jenderal Sudirman, Purwokerto, Central Java, Indonesia \\ *JI Dr. Soeparno, Purwokerto, Central Java, Indonesia; e-mail: afiatul.mukarromah@gmail.com
}

Submitted: $5^{\text {th }}$ May 2017; Revised: 30 ${ }^{\text {th }}$ October 2017; Accepted: $12^{\text {nd }}$ January 2018

\begin{abstract}
Demineralization is a process of partial or full tooth mineral loss which caused by acidic environment, for example the side effect of extracoronal bleaching treatment. Demineralization increases enamel surface roughness which leads plaque accumulation. Whey extract and calcium phosphopeptide-amorphous calcium phophate (CPP-ACP) contain calcium and phosphate that can stop the demineralization through remineralization process. This study aimed to determine the differences of enamel surface roughness after whey extract and CPP-ACP application post- extracoronal bleaching. Experimental laboratory with pre- and post-test control group design was performed on 24 first maxillary premolars which devided into 3 groups. On group I, specimens were immersed in artificial saliva. Specimens in group II were immersed in whey extract meanwhile specimens were immersed in CPP-ACP on group III. Whey extract and CPP-ACP immersions were conducted 10 minutes every 12 hours for 15 days. The enamel surface roughness test was performed twice, after extracoronal bleaching treatment and after 15 days remineralization agent application. This study result indicated significant differences between group I and group II and between group I and group III $(p<0.05)$, but there was no significant difference between group II and group III ( $p>0.05)$. This study showed whey extract decreased more enamel surface roughness than CPP-ACP but the difference was not significant statistically. So, whey extract and CPP-ACP showed similar remineralization potential.
\end{abstract}

Keywords: calcium phosphopeptide-amorphous calcium phosphate (CPP-ACP); demineralization; extracoronal bleaching; remineralization; whey ectract

\section{INTRODUCTION}

Clean, neat, and white teeth are known to have high aesthetic value and consequently they may increase one's self esteem. On the other hand, the occurrence of dental discoloration can disrupt one's appearance and lower one's confidence. Dental discoloration is divided into two types: extrinsic and intrinsic discoloration. The most common type of discoloration is extrinsic discoloration. Extrinsic discoloration is the coloration that occurs locally on the surface of the enamel. Extrinsic discoloration is attributed to food substances or colored drinks, cigarettes, betel nut lime, and others. ${ }^{1}$

In terms of dentistry, extrinsic discoloration raises aesthetic problems, which consequently encourages patients to seek improvement. One treatment to overcome extrinsic discoloration is extracoronal bleaching..$^{2,3}$ Extracoronal bleaching is performed with the principle of oxidation reaction of bleaching material to the tooth structure. One of the most commonly used bleaching materials is hydrogen peroxide $\left(\mathrm{H}_{2} \mathrm{O}_{2}\right)$. However, the bleaching material application of extracorporeal bleaching procedures is not free from side effects as it may lead to sensitive teeth and changes in enamel structure. Sensitive teeth were felt by $15-78 \%$ of post-bleaching patients. ${ }^{4}$ Research conducted by Heshmat et al. ${ }^{5}$ unveiled changes in microstructure that might take place after extracorporeal bleaching such as demineralization, degradation, increasing enamel microporosity, decreasing micro hardness, and increasing surface roughness of enamel. 
The surface roughness is the irregularity of enamel surface characteristics due to the demineralization process. ${ }^{6}$ Rough enamel surfaces predispose to bacterial attachment, bacterial maturation, and stain absorption. The accumulation of plaque on the post-bleaching teeth increased significantly on the fifth day compared with those without bleaching procedures. Accumulation of plaque may trigger caries and periodontal disease. Stain absorption leads to re-discoloration of teeth since the fifth week post bleaching. ${ }^{2,7}$

One method to avoid the extracoronal bleaching side effects is by applying remineralized materials. Remineralization material application aims to restore lost tooth mineral. This therapy generally applies some materials containing fluorine, calcium, and phosphate. The recommended remineralization materials for post-bleaching use are fluorine and casein phosphopeptide-amorphous calcium phosphate (CPP-ACP). ${ }^{4}$ CPP-ACP is a milk protein derivative which becomes the source of calcium and phosphate ions. The calcium and phosphate ions can replace damaged calcium hydroxyapatite structures, thus triggering the process of dental remineralization. ${ }^{4,7} \mathrm{~A}$ potential natural ingredients to be used as an alternative ingredient for remineralization is whey extract. Whey extract is a clear yellowish liquid which is a yogurt derivative or fermented milk. ${ }^{8}$

However, there has been no research focusing on surface roughness test after the extracoronal post-bleaching whey extract application, unlike the widely addressed surface roughness test of enamel after CPP-ACP application. Therefore the researcher's interest to test and compare the ability of remineralization of whey extract and CPP-ACP post extraloronal bleaching with surface roughness parameter.

\section{MATERIALS AND METHODS}

This study was conducted once it received an ethical clearance by the Medical Research Ethics Commission of RSUD Dr. Moewardi Surakarta (Number: 197 / III / HREC / 2017). The main ingredients to use in this study were whey extract and CPP-ACP (GC Tooth Mousse, GC, Japan). Whey extract to use in the study was made from frozen plain yogurt with thick consistency (YOBO, Yobo Nutrition, Banyumas, Indonesia). Whey extract was made by way of multilevel filtering method. In the first stage, yogurt was filtered using a white cloth to separate the whey with the curd. Then in the second stage, whey was filtered using a filter paper with a $1 \mu \mathrm{m}$ pore diameter to obtain a clear liquid whey extract. ${ }^{8}$

Twenty-four maxillary premolar teeth were cut horizontally $\pm 1 \mathrm{~mm}$ under the CEJ using a diamond disc bur with a water cooler. Dental crowns that had been cut were then grown in cold acrylic resins with buccal surfaces of teeth free from acrylic resins. The molds used for planting specimens were made of brass of $22 \mathrm{~mm}$ diameter and of $10 \mathrm{~mm}$ height. ${ }^{7,9}$

Forty percent of $\mathrm{H}_{2} \mathrm{O}_{2}$ bleaching material was applied to the entire enamel of tooth using a syringe and it was flattened with a tip. After 8 minutes, the bleaching material in the specimen was cleared using cotton. $\mathrm{H}_{2} \mathrm{O}_{2}$ was applied three times, which in total, amounted to 24 minutes. Afterwards, the research specimens were rinsed using aquades after the last $\mathrm{H}_{2} \mathrm{O}_{2}$ application. The surface roughness of the specimen enamel was immediately evaluated after the teeth whitening procedure. ${ }^{5}$ The dental specimens were then divided into three groups by simple random sampling, ie group I, group II, and group III. Each group consists of 8 specimens.

The specimens in group I were soaked in artificial saliva for 15 days and stored in an incubator at $37^{\circ} \mathrm{C}$. The artificial saliva was replaced every 12 hours. The specimens in Group II were soaked in whey extract for 10 minutes every 12 hours, while in group III the specimens were soaked in CPPACP for 10 minutes every 12 hours. Specimens soaked in either whey extract or CPP-ACP were subsequently soaked in artificial saliva and stored in an incubator at $37^{\circ} \mathrm{C}$. Treatment in groups II and III was repeated for 15 days. The second surface roughness test was performed after the treatment of the specimen on the 15th day (post-test). The application of remineralized material was carried out for 15 days because the average time required 
for CPP-ACP to take remineralization effect on the teeth after exposure to acid substances was at least 14 days. $^{5}$

Surface roughness tests on all specimens were performed in parallel at three different points: mesial, median, and distal. The distance between the three points is $1 \mathrm{~mm}$. The surface roughness was quantitatively tested using a profilometer (Surfcorder se-1700, Japan) with an accuracy of $0.004 \mu \mathrm{m}$, a precision level of $0.003 \mu \mathrm{m}$ and a $\mathrm{Rq}$ parameter. The profilometer main menu that is set includes the evaluation length of 1.6 to $2.4 \mathrm{~mm}$, the cut off value $(\lambda c) 0.8 \mathrm{~mm}$ and the constant speed of $0.5 \mathrm{~mm} / \mathrm{s}$. The roughness test was conducted at the laboratory of Mechanical Engineering Materials of Universitas Gadjah Mada (UGM).

The data of surface roughness test to be used for statistical analysis is the mean value $\Delta R_{q}$. The data were statistically analyzed using the Statistical Package the Social Sciences (SPSS) version 20. The first analysis addresses the normality test using Saphiro-Wilk method, while the homogeneity test uses Levene-test method. Paired T-test statistics were used to analyze $R_{q}$ immediately after extracoronal bleaching and postdental remineralization applications on day 15 of each group. One Way ANOVA statistic test was used to analyze $\Delta \mathrm{R}_{q}$ between groups, then Least Significance Difference (LSD) was tested with $95 \%$ confidence level or $\alpha=0.05$ to know whether there was any significant difference between specimen groups.

\section{RESULTS}

The mean and standard deviation (SB) of surface roughness of enamel before and after application of artificial salivary remineralization ingredient in group I, whey extract in group II, and CPP-ACP in group
III is illustrated in Figure 1. For further differences before and after treatment, the difference of surface roughness is presented in Figure 2 .

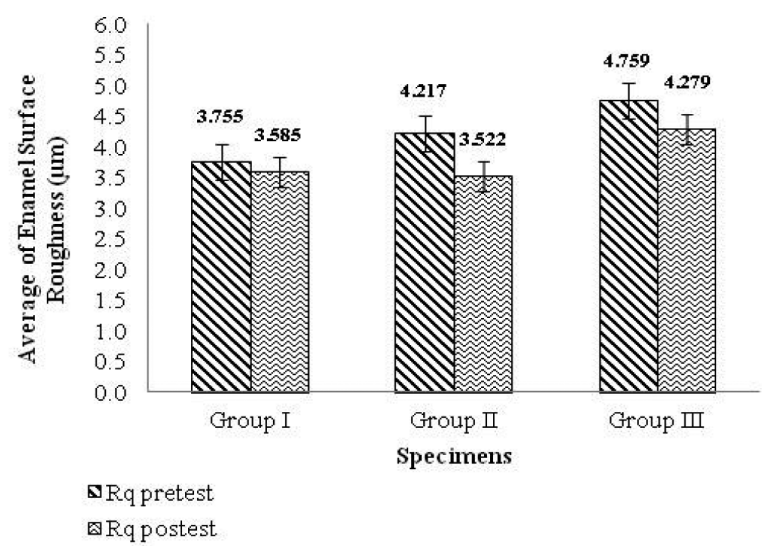

Figure 1. Graph of average surface roughness $(\mathrm{Rq})$ of enamel before (pre-test) and after (post-test) application of whey extract and CPP-ACP

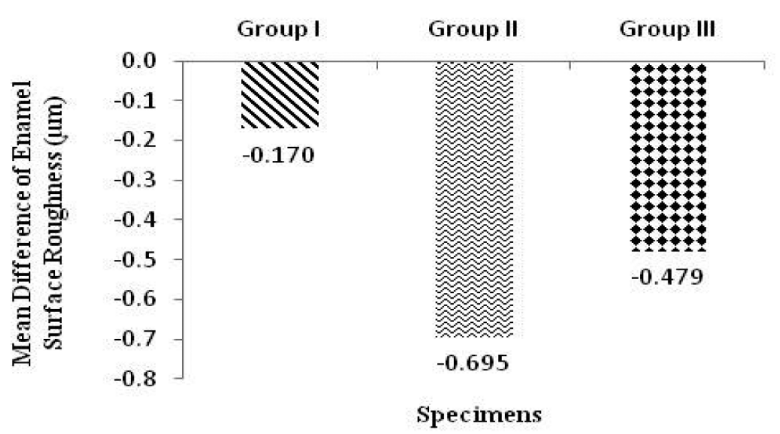

Figure 2. Graph of the mean difference of enamel surface roughness

The Saphiro-Wilk test proved that the data were normally distributed $(p>0.05)$ while Levene-test showed that the data were homogeneous ( $p>0.05)$. Result of Paired T-test statistic test to compare surface roughness of enamel before and after treatment in each group of specimen is summarized in Table 1. Paired T-test analysis indicated that in group I there was no significant decrease of surface roughness between that before and after saliva

Table 1. Paired T-test mean surface roughness before and after application of whey extract and CPP-ACP

\begin{tabular}{ccccc}
\hline \multirow{2}{*}{ No. } & \multirow{2}{*}{ Group } & \multicolumn{2}{c}{ Mean $(\mu \mathrm{m}) \pm$ Standart Deviation } & \multirow{2}{*}{ Sig } \\
\cline { 3 - 4 } & & Before & After & \\
\hline 1. & I & $3.755 \pm 0.910$ & $3.585 \pm 0.775$ & 0.058 \\
2. & II & $4.217 \pm 1.065$ & $3.522 \pm 1.068$ & $0.000^{*}$ \\
3. & III & $4.759 \pm 0.766$ & $4.279 \pm 0.805$ & $0.001^{*}$ \\
\hline
\end{tabular}

${ }^{*}=$ significant difference is $p<0.05$ 
Majalah Kedokteran Gigi Indonesia. April 2018; 4(1): 15 - 21

ISSN 2460-0164 (print)

ISSN 2442-2576 (online)

Table 2. Summary of significance value of post hoc test result of enamel surface roughness using least significance difference (LSD) method

\begin{tabular}{ccccc}
\hline No. & Group & I & II & III \\
\hline 1. & I & & $0.000^{*}$ & $0.017^{*}$ \\
2. & II & $0.000^{*}$ & & 0.083 \\
3. & III & $0.017^{*}$ & 0.083 & \\
\hline
\end{tabular}

* = significant difference $(p<0.05)$

application artificial with a value of $p>0.05$. The decrease of surface roughness was significantly different in group II and group III $p$ value $<0.05$.

Based on one-way analysis of variance (ANOVA), test with $\mathrm{F}=9.874$ and significance value of 0.001 , it is conclusive that there are significant differences of surface roughness between group I, group II, and group III ( $p<0.05)$. The summary of LSD test results can be seen in Table 2. The LSD test results present that there was significant difference between group I and group III ( $p<0.05$ ), but there was no significant difference between group II and group III ( $p>0.05)$.

\section{DISCUSSION}

The decrease of enamel surface roughness in group I, II, and III shows that there has been a process of remineralization on the teeth. Artificial saliva, whey extract and CPP-ACP contain calcium and phosphate minerals. Calcium and phosphate are the main minerals of hydroxyapatite crystals. Both minerals cause the process of remineralization that produces hydroxyapatite crystals. Such hydroxyapatite crystals decrease the interno-matic gap and microporosity of enamel, thereby decreasing the surface roughness of the enamel. Here are the general chemical reactions that occur in demineralization and remineralization processes..$^{5,10}$

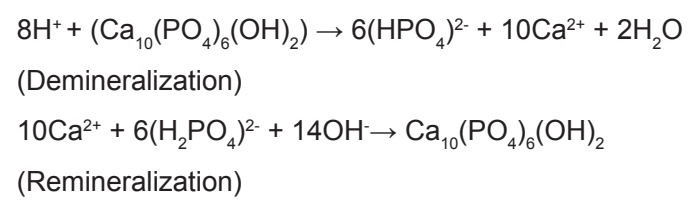

Damage to hydroxyapatite crystals is a sign of demineralization that begins with the presence of a bond between a phosphate ion $\left(\mathrm{PO}_{4}{ }^{3-}\right)$ of a hydroxyapatite crystal with a free $\mathrm{H}^{+}$ion which leads to the dissolution of apatite crystals. $\mathrm{H}^{+}$ion converts $\mathrm{OH}$-ions into $\mathrm{H}_{2} \mathrm{O}$ and converts $\mathrm{PO}_{4}{ }^{3-}$ ions into $\mathrm{HPO}_{4}^{2-}$. When contacting the acid, $\mathrm{HPO}_{4}{ }^{2-}$ ion will further turn into $\mathrm{H}_{2} \mathrm{PO}_{4}$. Remineralization can occur in the presence of calcium and phosphate that are the main minerals of hydroxyapatite crystals. Both minerals cause the process of remineralization which produces hydroxyapatite crystals. ${ }^{5}$

Whey extract contains calcium and phosphate ions and has a bufferability that plays an important role in the process of tooth remineralization. The process of remineralization begins with the attachment of whey proteins to the surface of demineralized enamel. The calcium and phosphate ions attach to dental plaque, resulting in a supersaturation state of calcium and phosphate minerals. The calcium and phosphate ions undergo a chemical reaction, thus forming a hydroxyapatite crystal. The formed hydroxyapatite fills the interprismatic gap of enamel, thus increasing the micro hardness and decreasing surface roughness of the enamel. ${ }^{8,11}$

The CPP-ACP remineralization process begins with the attachment and deposition of amorphous calcium phosphate in CPP-ACP at the surface and in the interprismatic gap of enamel. Calcium phosphopeptide binds calcium and phosphate in the form of nanoparticles, thus forming a stable mineral. CPP is able to stabilize calcium phosphate 110 times better than liquid solution at neutral $\mathrm{pH}$ and base before undergoing spontaneous precipitation process. ACP and crystalline form of dicalcium phosphate and octacalphosphate phosphate become intermediates of hydroxyapatite formation in the process of remineralization. ${ }^{9}$ These substances increase the density of the hydroxyapatite crystals and the density of the enamel prism. Increasing enamel prism density can decrease surface roughness. ${ }^{7,11,12,13}$ 
The decrease in surface roughness of enamel in group I was due to calcium and phosphate content in artificial saliva leading to the remineralization process. ${ }^{5}$ The decrease in surface roughness of group I enamel was not statistically significant. Several factors that may trigger a decrease in enamel surface roughness of group I are not significant, among others, the source of calcium and phosphate of group I is derived only from artificial saliva and calcium and phosphate content in non homogeneous homemade saliva.

Differences in the decreasing value of enamel surface roughness of each group occurred due to differences in mechanism and effectiveness of remineralized materials used. The effectiveness of the remineralization material is influenced by several factors such as the concentration and solubility of the remineralization material, the degree of acidity, temperature, complex forming reaction, the position of the balance point, and the chemical formulation of the remineralization material. ${ }^{14,15}$

The specimens of group II experienced the highest decrease in surface roughness. One of the factors resulting in the highest surface roughness of enamel in Group II is the $\mathrm{pH}$ of whey extract which is of 5.0-6.0. The low degree of acidity of whey extract can cause calcium and phosphate in the form of reactive ionized minerals, thereby increasing the remineralising power of whey extract. ${ }^{11}$ Remineralization materials having a $\mathrm{pH}$ of 4.5-5.1 can improve the process of tooth remineralization. An increase in the remineralization process can occur because the acidic $\mathrm{pH}$ is capable of increasing the absorption and mineral binding reaction in the enamelmatic gap of the enamel, so there is no significant mineral solubility of teeth. ${ }^{15}$

CPP-ACP has different mechanisms and potential of dental remineralization under conditions of carious lesions and erosion. Differences in the mechanism of remineralization occur due to differences in the characteristics of the structure of caries lesions and erosion. Erosive lesions have smaller pore structures and contain less organic material than carious lesions. This causes low CPP-ACP adhesion to the surface of the eroded tooth. Low CPP-ACP adhesion to erosive lesions leads to penetration of calcium and phosphate into the interobacial gap of declining enamel. These conditions may disturb the process of remineralization of teeth, thereby leading to less maximum formation of hydroxyapatite crystals. The formed hydroxyapatite crystals cannot conceal the interprismatic gap of enamel formed after maximal extracoronal bleaching procedures, resulting in less optimal maximal surface roughness. ${ }^{14,16}$

The process of dental remineralization in erosive lesion conditions is associated with deposition and mineral reactions into the interprismatic gap of enamel. The minerals in the remineralized material react directly to the surface of the eroded teeth. The remineralization mechanism can be performed by whey extract because it contains reactive calcium and phosphate ions. The calcium and phosphate ions will react directly to the interprismatic gap of enamel to replace the minerals lost due to extracoronal bleaching procedures. The reaction improves the process of closing the intermo-matic gap of enamel and decreasing enamel porosity, resulting in a decrease in the surface roughness of the enamel. This mechanism which is one of the causes of whey extract has decreased surface roughness of enamel higher than CPP-ACP. ${ }^{11,15,16}$

One Way ANOVA statistical analysis was used to compare the presence or absence of significant differences between group I, group II and group III. The results of One Way ANOVA statistical analysis in this study revealed that there were significant differences in surface enamel roughness between group I, group II and group III. The result of LSD test analysis showed that there was significant difference of surface enamel roughness between group I with group II and group III but there was no significant difference of surface enamel roughness between group II and group III. The decrease in enamel surface roughness between group II and group III which was not significant in the LSD test indicated that

Whey extract and CPP-ACP had the same potential as dental remineralization materials after being exposed to extracoronal bleaching procedures. Thus, whey extract can be used as an alternative remineralization material to replace CPP-ACP 
to decrease surface roughness that occurs after extracoronal bleaching. The results of this study are in line with the research conducted by Heshmat et al. ${ }^{5}$ and Ferrazano et al. ${ }^{11}$ Heshmat et al. ${ }^{5}$ indicating that CPP-ACP can decrease surface roughness after the extracoronal bleaching procedure, while Ferrazano et al. ${ }^{11}$ proved that yogurt as a whey extract was able to decrease the surface roughness of enamel on the demineralized teeth.

\section{CONCLUSION}

The research analysis had shown that the surface roughness of enamel after the application of whey extract was lower than CPP-ACP and artificial saliva. Statistical analysis unveiled that there was no significant difference between the application of whey extract and CPP-ACP post extracoronal bleaching, but both had significant differences with artificial saliva. Based on the results of the research and statistical analysis, whey extract can replace CPP-ACP to decrease surface roughness that occured after extracoronal bleaching.

\section{ACKNOWLEDGEMENT}

The authors would like to extend gratitude to the head of the laboratory of Mechanical Engineering Materials of Universitas Gadjah Mada (UGM) and all those who have assisted in the research process and the preparation of this research article.

\section{REFERENCES}

1. Hendari R. Pemutihan gigi (tooth-whitening) pada gigi yang mengalami pewarnaan. J Sultan Agung. 2009; XVIV(128): $65-78$.

2. Gursoy UK, Eren DI, Bektas OO, Hurmuzlu F, Bostanci V, Ozdemir H. Effect of external tooth bleaching on dental plaque accumulation and tooth discoloration. J Med Oral Patol Oral Cir Buccal. 2008; 14(4): E266 - E269.

3. Torabinejad M, Walton RE. Endodontics principles and practice $4^{\text {th }}$ edition. Malaysia: Saunders Elsevier; 2013. 391 - 402.

4. Yesilyurt C, Sezer U, Ayar MK, Alp CK, Tasdemir T. The effect of a new calcium-based agent, pro- argin, on the microhardness of bleached enamel surface. Aust Dent J. 2014; 58: 207 - 213.

5. Heshmat H, Ganjkar MH, Jaberi S, Fard MJK. The effect of remin Pro and MI paste plus on bleached enamel surface roughness. J Dent Tehr Univ Med Sci. 2014; 12(2): 141 - 146.

6. Cross SE, Kreth J, Wali RP, Sullivan R, Shi W, Gimzewski JK. Evaluation of bacteria-induced enamel demineralization using optical profilometry. J Dent Mat. 2009; 25(13): 1618 - 1626.

7. Divyapriya GK, Yavagal PC, Veeresh DJ. Review article casein phosphopeptide - amorphous calcium phosphate in dentistry: an update. Int $\mathrm{J}$ Oral Health Sci. 2016; 6: $18-25$.

8. Rezvani MB, Karimi M, Rasoolzade RA, Haghgoo R. Comparing the effects of whey extract and case in phosphopeptide-amorphous calcium phosphate (CPP-ACP) on enamel microhardness. J Dent Shiraz Univ Med Sci. 2016; 17(1): $49-53$.

9. Özkan P, Kansu G, Özak ŞT, Yilmaz SK, Kansu $P$. Effect of bleaching agents and whitening dentifrices on the surface roughness of human teeth enamel. Acta Odont Scand. 2013; 71: $488-497$.

10. Dawes $C$. What is the critical ph and why does a tooth dissolve in acid. J Can Dent Assoc. 2003; 69(7): $22-24$.

11. Ferrazzano GF, Cantile T, Quarto M, Ingenito $A$, Chianese L, Addeo F. Protective effect of yogurt extract on dental enamel demineralization in vitro. Aust Dent J. 2008; 53: 315 - 319.

12. Alaghemand $\mathrm{H}$, Kamangar $\mathrm{SSH}$, Zarenegad $\mathrm{N}$, Tabari N, Abedi $\mathrm{H}$, Khafri S. In-vitro effect of casein phosphopeptide-amorphous calcium phosphate on enamel susceptibility to staining by tea during bleaching treatment. J Dent Tehr Uni Med Sci. 2015; 13(8): 607 - 614.

13. Mettu S, Srinivas N, Sampath R, Srinivas N. Effect of casein phosphopeptide-amorphous calcium phosphate (CPP-ACP) on caries-like lesion in terms of time and nano-hardness an in vitro study. J Ind Soc Pedo Prev Dent. 2016; 33(4): $269-273$. 
14. Amaral CM, Miranda MESNG, Correa DS, Silva EM. Sodium fluoride and casein phosphopeptideamorphous calcium phosphate cream plus sodium fluoride efficacy in preventing enamel erosion in a simulated oral environment study model. Indian J Dent Res. 2015; 24(4): 464 - 469.

15. Ambarkova V, Goršeta K, Glavina D, Škrinjaric I. The effect of fluoridated dentifrice formulations on enamel remineralization an microhardness after in vitro demineralization. Acta Stomatol Croat. 2012; 45(3): 169 - 175.
16. Alencar CRB, Magalhães AC, Machado MAAM, Oliveira TM, Honório HM, Rios D. In situ effect of a commercial CPP-ACP chewing gum on the human enamel initial erosion. J Dent. 2015; 42: $1602-1607$. 